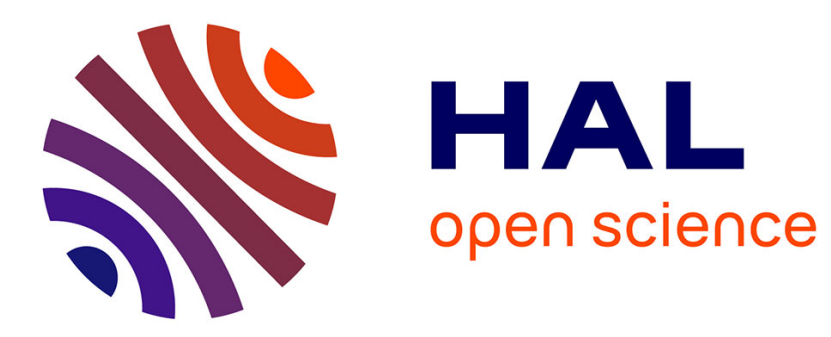

\title{
Amphores et céramique de l'épave de Marseille
}

Fernand Benoit

\section{To cite this version:}

Fernand Benoit. Amphores et céramique de l'épave de Marseille. Gallia - Fouilles et monuments archéologiques en France métropolitaine, 1954, 12 (1), pp.35-54. 10.3406/galia.1954.1361 . hal01924494

\section{HAL Id: hal-01924494 \\ https://hal.science/hal-01924494}

Submitted on 3 Mar 2020

HAL is a multi-disciplinary open access archive for the deposit and dissemination of scientific research documents, whether they are published or not. The documents may come from teaching and research institutions in France or abroad, or from public or private research centers.
L'archive ouverte pluridisciplinaire HAL, est destinée au dépôt et à la diffusion de documents scientifiques de niveau recherche, publiés ou non, émanant des établissements d'enseignement et de recherche français ou étrangers, des laboratoires publics ou privés.

\section{(이) $\$$}

Distributed under a Creative Commons Attribution - NonCommercial - NoDerivatives| 4.0 


\title{
AMPHORES ET CÉRAMIQUE DE L'ÉPAVE DE MARSEILLE
}

\author{
par M. Fernand BeNoIT
}

Les premiers résultais de la fouille de l'épave du Grand Congloué, entreprise par le Commandant J.-Y. Cousteau à bord de la Calypso (fig. 1), avec la collaboration de la Direction des Antiquités, le 15 août $1952^{1}$, permettent de donner une classification provisoire de l'important matériel céramique comprenant des amphores de types différents ${ }^{2}$, de la vaisselle campanienne et quelques fragments de "bols de Mégare ". Nous nous bornerons ici, en attendant la publication de l'étude générale portant sur l'épave elle-même, qui ne pourra être faite qu'à l'achèvement des fouilles, à donner la typologie des amphores et de la céramique campanienne qui appartiennent à deux régions différentes, la Grèce et la Grande Grèce.

L'épave, profondément ensablée, affaissée sur elle-même et ícrasée sur la pente de la falaise, entre 36 et 45 mètres de fond, couvre une superficie approximative de $28 \mathrm{~m}$. sur 8 . Les coupes des tranchées de dévasage faites l'une au Nord (proue ?), l'autre au Sud (poupe ?), à proximité immédiale du récif, montrent la hauteur du chargement empilé sur le pont et l'entrepont : le nombre d'amphores remontées, entières ou brisées, dépasse 2.000, ce qui représenterait moins de la moilié de la cargaison. Le tonnage du navire ne peut être évalué, faute d'en connaître les proportions et le profil, la longueur de la quille et la largeur des membrures; cependant il est vraisemblable, si l'on chiffre le poids du fret à quelque 500 tonnes, d'évaluer le jaugeage à un millier de tonneaux. C'est à un tonnage de cette importance, 1.250 à 1.300 tonneaux, que le Professeur Lionel Casson a évalué la capacité de l'Isis, décrit par Apulée dans son Navigium, en se fondant sur les rapports de longueur de la quille et du rayon : une telle capacité ne ser'a ulleinte à nouveau qu'au

(1) Cf. Gallia, XI, 1953, 1, p. 103-106.

(2) La nomenclature au supplément de la tỵpologie des amphores de Dressel-Pélichet, comprenant les nouvelles formes signalées par M. Almagro et provenant des fouilles sous-marines de Provence, sera publiée dans Gallia. 
xixe siècle, avec les progrès de la navigation ${ }^{3}$. L'épave de Marseille n'a pas encore livré tous ses secrets; mais du moins, l'hypothèse, un instant envisagée ${ }^{4}$, de la superposition de deux navires, l'un gree au fond, l'autre ilalique au-dessus, - si conforme à la stratigraphie des fouilles terrestres, el probable dans certains "nids" d'épaves de la côte (Sanary, îles Lavezzi), — ne peut être retenue à cause de la posilion même du fret, comprenant dans l'entrepont et la cale les amphores rhodiennes et la vaisselle campanienne el, dressées sur le pont, les amphores italiques.

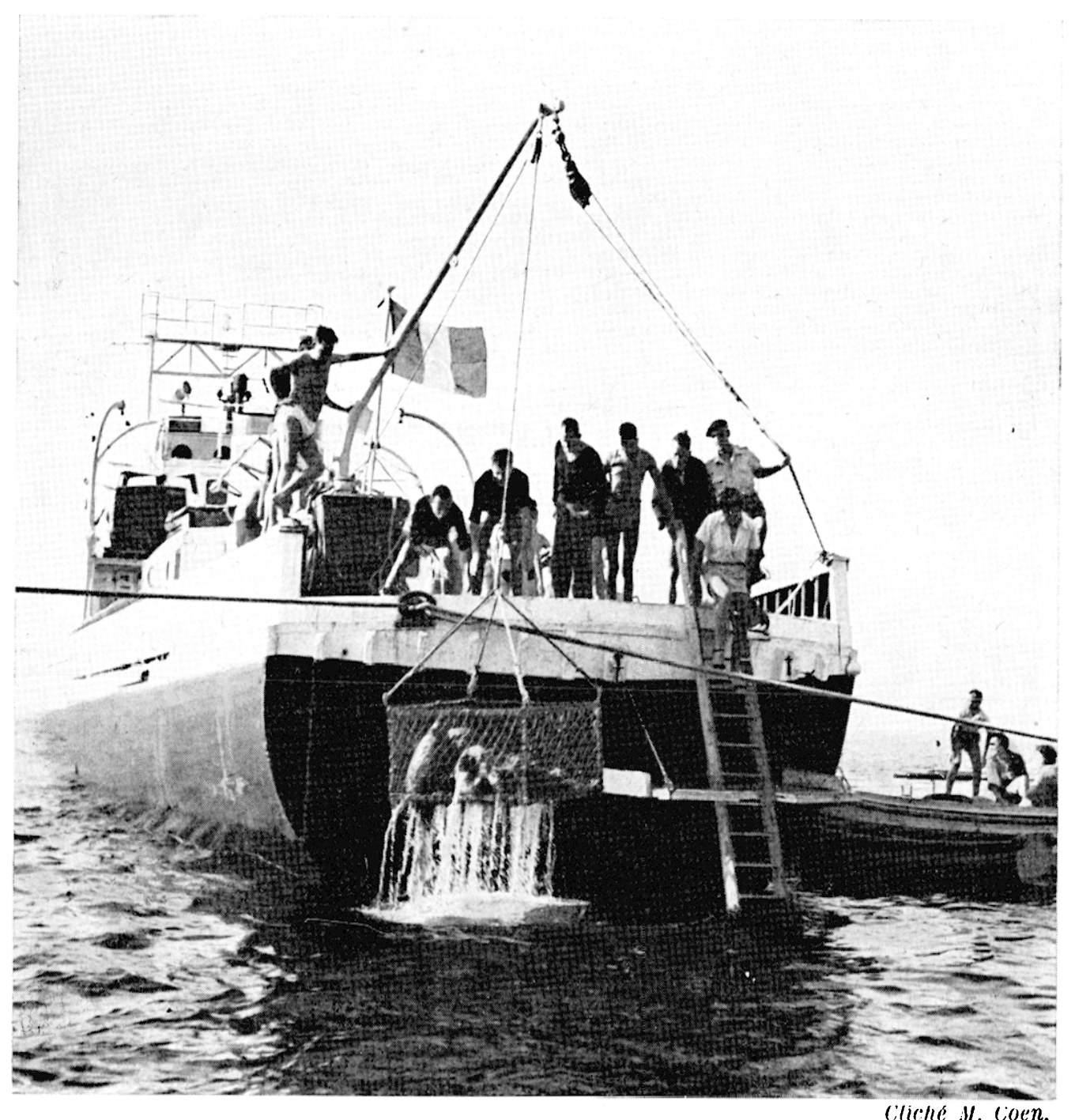

Fig. 1. - Remontée du panier d'amphores à bord de la « Calypso».

(3) The Isis and her Voyage, in Transactions of the American Philological Association, LXXXI, 1950 , p. $43-56$.

(4) F. Bkxort, Naissance de l'archéologie sous-marine, dans Neplunia, Paris, n $31,1953$. 

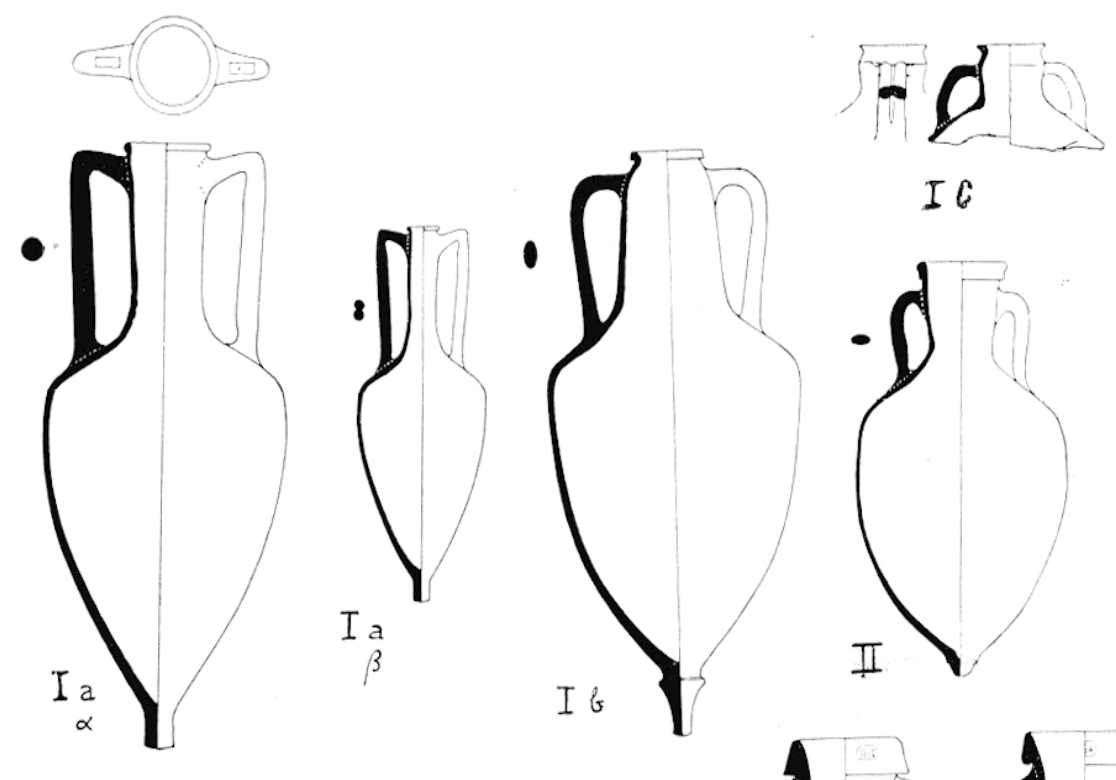

I6
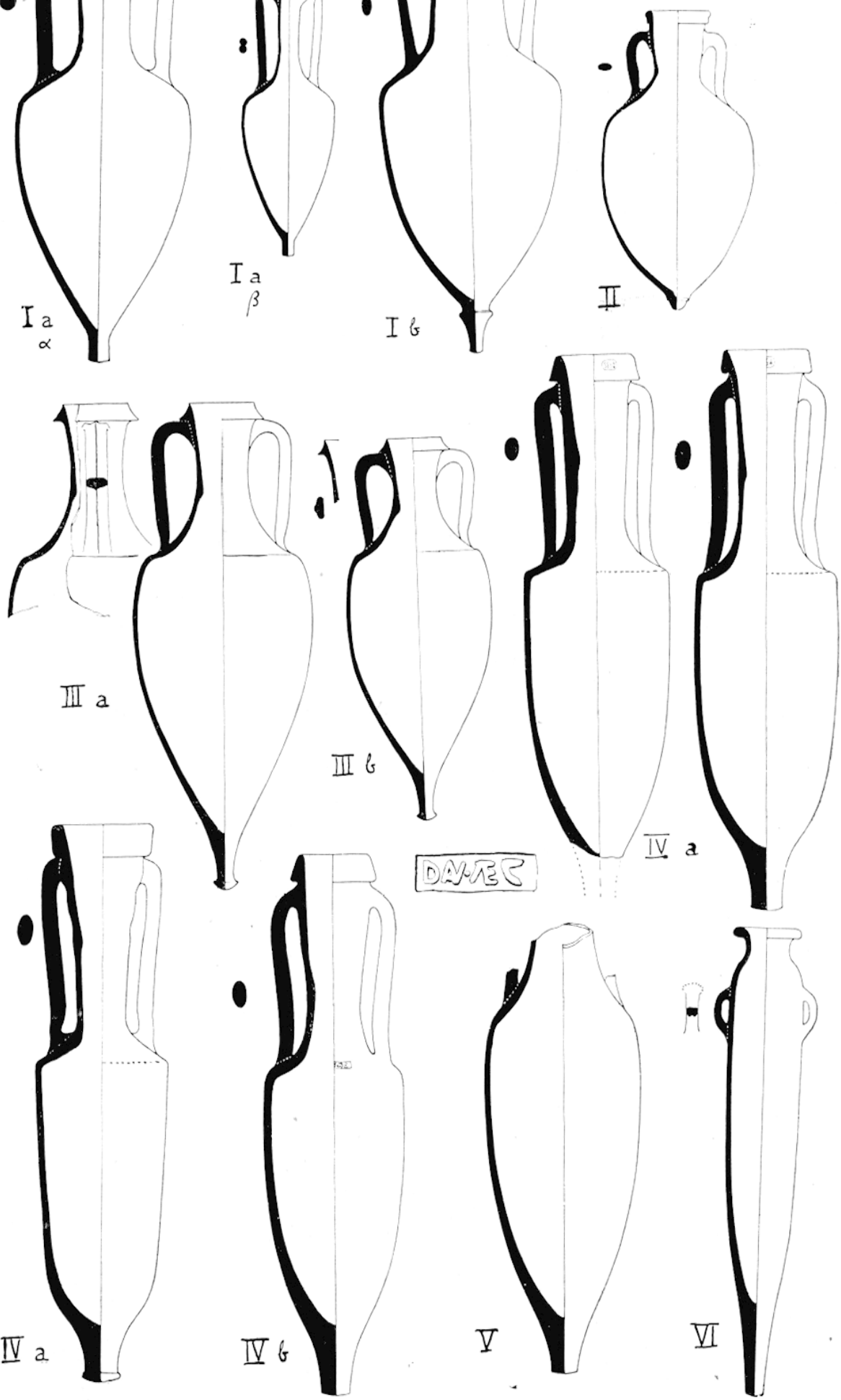

FiG. 2. - Types d'amphores. - I a, $\alpha$ : Rhodes, grand modè'e, li. : 0m,80. - I a, $\beta$ : Rhodes, petit modèle, h. : $0 \mathrm{~m}, 50$ (cf. fig. 3). - I b : Cnide, h. : 0m,79 (cf. fig. 4). I c : co', de type inédit. - II : grecque, en forme de toupie, h.: $0 \mathrm{~m}, 65$. - III a : gréco-italique, grand modèle, h. : $0 \mathrm{~m}, 88-90$. - III b : gréco-ilalique, petit modèle, h. : 0m.63. - IV a : romaine, de SES., h. : $1 \mathrm{~m}, 02$ (cf. fig. 5 et 6 ). -- IV b : romaine, de DAV.ATEC, h. : 0m,98 (cf. fig. 7 ). - V : romaine, a profil fusele, l. sans le col : 0m,83. - vi : punique, h. : $0^{\mathrm{m}}, 82$. 
Le synchronisme du maléricl oblige done à retenir pour probable la datation donnée par les pieces dont la forme appartient a la plus ancienne époque, amphore de Rhodes, bol hellénistique à relief, guttus et lampes de Campanie, et à circonscrire le naufrage vers $200-175$ av. J.-C.

\section{A) LES AMPHOLES}

Elles se classent selon 6 types :

I. - Amphore grecque, à embouchure à collerette en forme de bourrelet étroit, a panse en forme de toupie, avec jonction curviligne jet non à arête vive) du col à la panse.

a) Amphore de lihodles: la partic supérieure de l'anse, légèrement remontante, se raccorde avec la partie inférieure par une jonction abrupte, l' " angle rhodien ". L'argile, bien épurée, présente à la cassure un noyau rouge, entouré d'une pâte rose.

Il y a deux tailles différentes:

a. Six exemplaires de grand modèle (fig. 2, Iax), plus ou moins complets, dont l'un intact (haut.: $0 \mathrm{~m}, 80$ ); l'anse est lisse. Flles portent toutes une marque sur la partie supérieure de l'anse: 4 rectangulaires, 2 circulaires avec la rose, indéchiffrables par usure sous la couche de corrosion calcaire. Te profil de l'anse les fait entrer dans la seconde moitié du III $^{\mathrm{e}}$ siècle, selon la typologie de Miss Virginia Grace 5.

$\beta$. Scize exemplaires de petit modèle (fig. 2, Ia $\beta$ ), dont six complets (haut.: $0^{\mathrm{m}}, 50$ ). L'anse est bifide (fig. 3), mais sans la profonde síparation entre lez deux nervures, qui raratérise les anphoress de cos. Lne seule porte une petite marque carrée sur le coude, peu apparente en raison de la feuillure entre les deux nervures (Nusée Borély, no 8449). Toutes ces amphores ont été trouvées en 1953, dans la tranchée de dévasage (còté sud, en poupe ?). - On comparera une amphore rhodienne de plus petit modèle $\left(0^{\mathrm{m}}, 3 \tilde{7}\right)$, sans marque, à anse bifide, trouvéc dans le gisement de l'oppidum de la Teste Nègre, aux Pennes, près de Marseille ', gisement remarquable par l'analogie de ses amphores et de sa céramique campanienne avec les types de l'épave du Grand Congloué.

(5) Excatations in the Athenian Agora. Stamped Amphora Ilandles, dans Ilesperia, III, 1934, p. 203, fig. 1 et 5 et pl. II, 5 ; ef. de la même : The Eponyms named on Rhodian Amphora Stamps, ibid., XXII, 1953, pl. 42. Cette forme d'anse est nettement postérieure a l'anse curviligne de la première moilié du III siècle (IIesperia, l. l., pl. II, 4), trouvée dans les fouilles de Marseille (marque reclangulaire EIIfEYPA NOPISA : Vicille Poissonnerie, II, 2 G 343 ). Je tiens a remercier Miss V. Grace et MM. Jannoray et Lueis $\Lambda$. Benachi de leurs indications : deux des marcfues sur limbre rectangulaire donnent le nom du fabricant rbodien Aprotiov el de l'séponyme Kderrónzxos lrourés a Dílos, vers 200: la rose des timbres circulaires est a rapprocher de celle des amphores d’Aporoxiñs (200-180 ar. J.-G.), dont les timbres ont élé relrourés a Délus : V. Ginatl, Timbres amphoriques troutés à Délos, dans le Bull. Corr. hellénique, т6. 195\%, p. 5\%6 el pl. XXIII. fig. 29.

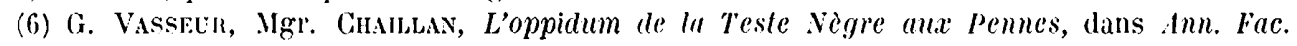
des sciences de Marsille, XXIV, 2, 1917, pl. I, 3; DÉchedette, Man. Arch. préhistorique, II, 3, p. 1002, fig. 420, 5 . 
b) Amphore de cride (haut.: $0^{\mathrm{n}}, 79$ ), caractérisée par la présence d'un annelet à la naissance de la pointe (fig. 2, Ib, et fig. 4). Le col est bordé d'un étroit bourrelet, souligné par une gorge profonde qui rétrécit l'embouchure. Ie profil de l'anse non nervée, rurviligne, avec infléchissement vers l'intérieur de la partie descendante, se rapproche de l'amphore de Thasos des IVé-III $^{\mathrm{e}}$ siècles ${ }^{8}$. La pâte, bien épurée, légèrement micacéc, à la cassure présente un noyau rouge. Un exemplaire a été trouvé dans la couche superficielle en 1952 et une base avec annelet en 1953 (tranchée sud), tous deux corrodés.

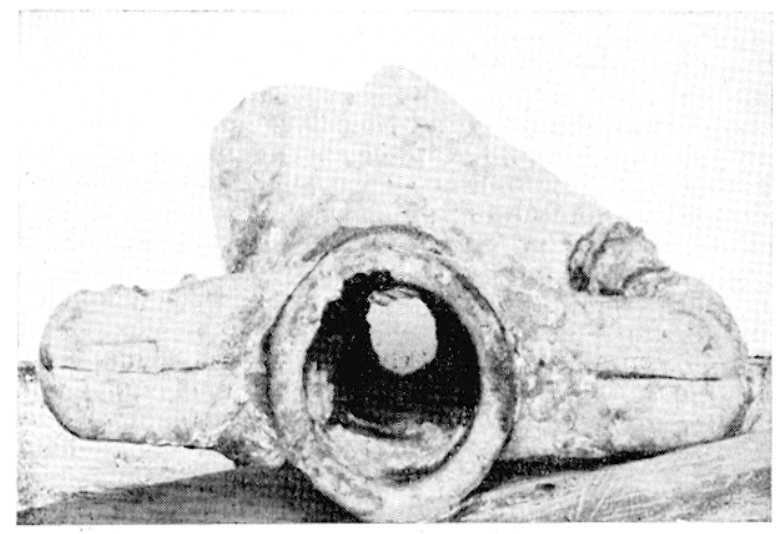

FIG. 3. - Amphore de Rhodes, petit modèle, type I a $\beta$ (fig. 2): le col, à anses bifides, avec marque d'origine à gauche.

FiG. 4. - Amphore de Cnide, type Ib (fig. 2). haut. : $0 \mathrm{~m}, 79$

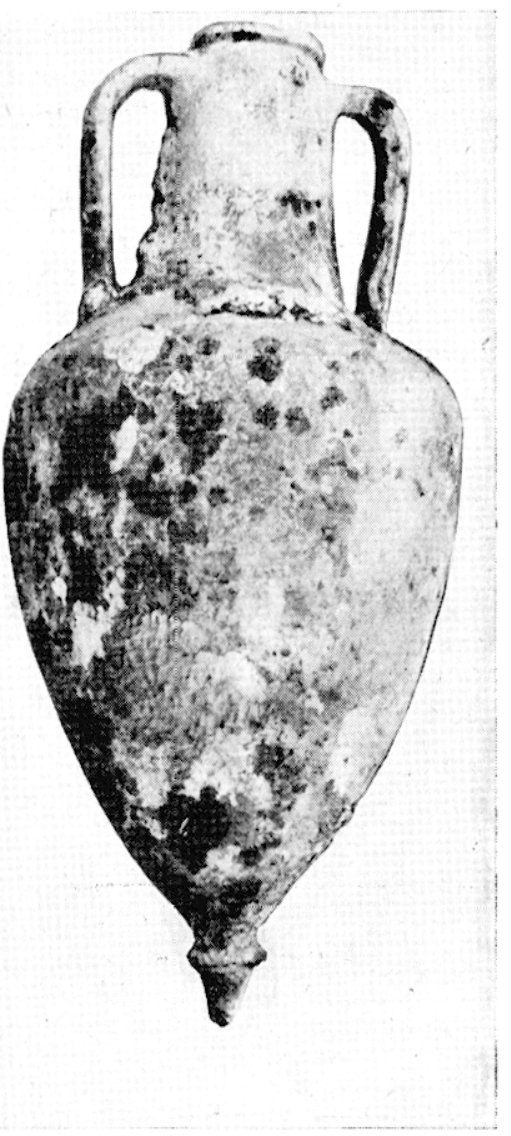

c) Un col d'amphore analogue, également sans marque et de pâte semblable, est remarquable par le peu de hauteur du col, plus trapu que dans l'amphore précédente, saillant sur une épaule arrondie; les anses bifides, courtes et arquées, se raccordent à la panse selon une ligne oblique à l'axe de l'amphore (fig. 2, Ic). Trouvé avec la précédente en 1952, ce col appartient à un type non identifié. On en rapprochera les frag. ments signalés à Thasos dans un gisement hellénistique, et à l'agora d'Athènes (SS 5265) 0 .

(7) V. Grace, $l$. l., p. 202, fig. 1,6 et pl. II, 6.

(8) Ibid., p. 203 et pl. II, 2 et 3.

(9) J. Deshayes, Bull. Corr. hell., LXXVI, 1952, p. 273 et fig. 75. 
II. - Amphore grecque, à embouchure ì collerelte en forme de bourrelet large, à panse en forme de toupie, avec ípaulement curviligne (haut. : $0^{\mathrm{m}}, 52$; fig. 2). Les anses curvilignes sont lisses; la pointe cylindrique est en forme de bouton.

Ce type d'amphore est voisin d'un exemplaire (haul. : $\left({ }^{\mathrm{m}}, 68\right)$ trouvé dans l'oppidum de la Teste Nigre aux Pennes ${ }^{10}$, en conjonction avec des amphores rhodiennes et puniques. Il est à rapprocher d'amphores grecques de la nícropole à incinération de Las Corts à Ampurias (haut.: $0^{\mathrm{m}}, 46$; diam. de l'embouchure : $\left.{ }^{(m}, 13\right)$, de la fin du III $^{\mathrm{e}}$ siècle ${ }^{11}$, de la nécropole de Thapsus en Byzacène ${ }^{12}$ el de la nécropole grecque de Gênes (haut. : $0^{\mathrm{m}}, 625$; diam. : $0^{\mathrm{m}}, 335$ ), eette dernière en conjonction avec des vases attiques du Ive siècle ${ }^{13}$.

Lne amphore analogue a été trouvée par A. Maiuri dans le dépôt d'amphores de Rhodes ${ }^{13 i s i s .}$

La pâte en surface jaune clair, bien épurée, se rapproche de celle des amphores rhodiennes et cnidiennes. Ce type jusqu'ici unique dans les gisements de l'épave est caractérisé par l'apparition d'un rebord à collerette en place du bourrelet des amphores grecques.

III. - Amphore gréco-italique, formant transition entre le type grec et le type "romain ". Comme la sćrie rhodienne, ce type est de deux tailles différentes : a) grand modèle: haut. $0^{\mathrm{m}}, 88-90$, diamètre du haut de la panse: $0^{\mathrm{m}}, 63$ (fig. 2, IIIa); - b) petit modèle : haut. $0^{\mathrm{m}}, 63$, diamètre du haut de la panse : $0^{\mathrm{m}}, 28$ (fig. $\left.2, \mathrm{IIIb}\right)$.

Le col, de profil idenlique, bitronconique (l'étranglement servant à la fermeture), largement ouvert a l'embouchure (diam.: $0^{\mathrm{m}}, 13$ et $0^{\mathrm{m}}, 105$, mesures internes), est terminć par une collerelte à lèvre inclinće, qui constitue le prototype des amphores italiques; largement évasé vers le bas, il se raccorde à la panse à la naissance des anses. L'épaulemenl, au lieu d'être curviligne comme dans l'amphore grecque, est nellement raccordé à la panse dont il est séparé par une arête. La pointe effilće, issue du type précédent et fragile, est terminće par un empàtement lígèrement conique, issu du bouton. Les anses à coude curvili-

(10) G. Vasseur, Mgr. Challan, $l$. l., pl. 1, 6; J. Décheletetl, o. $l$., p. 1002, fig. 420,4 et 6.

(11) Martin Alaragro, Las necrópolis de Ampurias, I, Barcelone, 1953, p. 389, fig. 392 et p. 399 , fig. 28 .

(12) P. Cin'ss, Céramique punique, Paris, 1950, p. 153 et pl. XXVI, n 322 ; cf. J. Déchelette: o. l., flg. $421,3$.

(13) B. BREA, dans Rev. Et. ligures, 1951, p. 181, fig. 21 (tombe IV = 112) avec cratères a calice et en forme de cloche, attiques.

(13 bis) Una fabbrica di anfore rodie, in Annuario della Regia Soc. arch. di Atene, IV-v, 1924, fig. $6, n^{\circ} 4569$. 
gne. suivant le profil le plus général enGreee. sont neflement détachérs du col et s’infléchissent vers l'inlírieur dans la partir descrendante; elles sont toujours renflées au milieu par un filet longitudinal, en saillie, sans marque. La pâte, plus grossiere el friable que celle des amphores grecques, est ígalement différente de celle des amphores romaines. Peu cuite, pleine de grains de calcile et de tuileaux concassés, légèrement micacée, elle a une couleur variant du gris au jaune clair, avec manque de cuisson dans la parlie interne, qui est grise. L'une d'elles eependant, incomplite du haut de la panse, est en pâte rougeatre, très cuite. I'ne autre, de pelit modele. est ì panse curviligne et à pàte sans tuileaux, avec particules noires.

Io lieu ou les lieux de fabrieation de ces amphores sont inconnus. On en rapprochera une amphore incomplète (liaut.: $0^{\mathrm{m}}, 88$ ) à lèvre également inclinée, trouvée à Rhodes par Miss V. Grace 1t. Mais elles sont nombreuses en Grande Grèce, à Tarente, à Lerce. à Paestum, à Ischia deux exemplaires trouvés en mer, au Museo dell'sola), en Afrique méditerranéenne (Alger et Tunis) 15. In exemplaire intact a été retiré de l'eau dans l'étang de l'Estomac à Fos ${ }^{16}$. Deux exemplaires analogues, de petit modèle ((1).54), à l'oppidum des Pennes (Vassetr-Chall,ax, I. 1., pl. I, 2), à pâte grisâtre arec tuileaux concassés bruns, à surface lisse légèrement micacée (Borély, 11619 et 11620)17.

Deux épaves ont été reconnues récemment, l'une à Anthéor, à $300 \mathrm{~m}$. de la balise la Chrétienne, par M. J. Charvoz et le "Club Alpin sous-marin " de Cannes (épave C de la Chrétienne); l'autre à la balise du Prètr', aux îles Lavezzi, en Corse, par M. A. Davso ì bord de la Calypso (août et juillet 1953). La pâte des amphores que contenaient ces épares, légèrement micacée, très cuite, variant du jaunâtre au rouge, sans couche grise interne, semble dépourvue de tuileaux concassés, mais parait contenir certaines particules minérales provenant d'une région volcanique. Elle est plus homogène que la majorité des amphores de l'épave de Varseille, mais se rapproche de l'amphore à pâte rouge, jusqu'ici unique, trouvée dans ce lot. - Un fragment de col d'amphore analogue, de pâte jaunâtre avec des cristaux de même nature, a été recueilli à Délos dans les déblais de la "villa du Trident " (expédition de la Calypso, 1953).

IV. - Amphore romaine, plus haute que les précédentes, mais de moindre capacité (19) litres); elle a une forme toute différente et constitue par sa datation le prototype de l'amphore romaine (type I de Dressel). Le plus ancien exemple connu étail à ce jour celui de l'oppidum d'Entremont, de peu antérieur à la destruction (123 av. J.-G.) : ses nombreux exemplaires retrouvés sont remarquables par la diversité de profil de leur collerette rectiligne, parfois con-

(14) F. Bexort, L'archéalogie sous-marine en Prorence, dans Rerue d'Etudes Ligures, 1952. p. 248 , fig. 11 .

(15) L. Leschi, L'Algérie antique, 1952, p. i5; une autre venant du Cap Ténès, au Musée de la Marine a Paris.

(16) F. BExolt, l. l., p. 288.

(17) Haut. (pied manquant) $0^{\mathrm{m}}, 80$; diam. $0^{\mathrm{m}}, 33$ : Borély, 8470-8474. 
cave, le plus souvent oblique, parfois à lèvre inclinće vers l'intérieur. Elles n'ont pas de marque, sauf exception unique, trouvée en 1953 : CL. ? E, inscrite en relief sur le col, dans un carlouche rectangulaire mal estampé $\left(0^{\mathrm{m}}, 020 \times 0^{\mathrm{m}}, 014\right)$.

Les amphores de l'épave marseillaise appartiennent à deux fabriques (fig. 2, IV a et $\mathrm{b})$ :

a) La majorité (haut.: $1^{\mathrm{m}}, 02$; diam. en haut de la panse: $0^{\mathrm{m}}, 25$ à $0^{\mathrm{m}}, 27$ ) portent un timbre au nom de SES(tius) sur le col (fig. 2, IVa, fig. 5 et 6), une fois exceptionnellement à l'attache de l'anse sur l'épaule (LI.2.566 : col de l'amphore cassé). Cette marque représente la plus grosse partie du fret remonté (1700 amphores entières ou brisées).

b) Sept exemplaires seulement, incomplets du col, mais en partie reconstitués, se distinguent des précédents par une hauteur légèrement moindre et une panse plus arrondie (haut.: $0^{\mathrm{m}}, 98$; diam. en haut de la panse, $0^{\mathrm{m}}, 28$ à $0^{\mathrm{m}}, 30$ ); la lèvre du col est oblique. Elles portent une marque, à la naissance de l'épaule, comprenant deux groupes de lettres ligaturées dans un cartouche rectangulaire DAV.ATEC (fig. 2, IVb, fig. 7).

Le profil de ces amphores marque une transition avec la forme grecque. La panse plus large en haut qu'en bas, selon le type "toupie ", surtout dans les amphores du second timbre, a tendance à adopter une forme cylindrique en " obus ", avec brusque courbure à la base, qui se termine par un pied massif cylindrique, constituant un véritable manche de préhension, servant au chargement sur l'épaule. Le col très allongé mesure parfois les $3 / 4$ de la hauteur de la panse; plus évasé en haut qu'en bas, selon la forme tronconique, il se raccorde à la panse par un épaulement à arête plus ou moins vive déterminant un angle obtus, déjà apparent dans la série précédente. Ce col présente une série de cannelures intérieures, parfois même un étranglement destiné à maintenir le bouchon en place et à faciliter la fermeture. Les lèvres ont un profil variable, oblique dans le second type, ayant tendance à la verticalité dans le premier, le diamètre de l'embouchure variant entre $0^{\mathrm{m}}, 155$ et $0^{\mathrm{m}}, 175$, avec moyenne de $0^{\mathrm{m}}, 16$ (mesures extérieures). La collerette est toujours séparée du col par une profonde gorge. Les anses rectilignes avec coude brusque sont verticales et très rapprochées du col. - La pâte, très cuite $\left(450^{\circ}\right.$ max.), de couleur rouge brique, est plus épaisse que celle des amphores grecques avec parfois des boursouflures; elle est très résistante et ne s'effrite pas. L'analyse au microscope a révélé des traces de cristaux provenant de cendres volcaniques (augite d'alumine, obsidienne) qui sont reconnaissables dans les amphores moins anciennes d'Entremont, de la Graufesenque (L. Balsan) et de Bâle, et qui dénotent une même provenance napolitaine des II $^{\mathrm{e}}$ et $\mathrm{I}^{\mathrm{er}}$ siècles 18 .

V. - Amphore romaine, à profil fuselé (fig. 2, V). Une amphore, incomplète du col, a été retiréc de l'épave en 1053 (Borély 8460 : hauteur subsistante. $0^{\mathrm{m}}, 83$; diamètre du haut de la panse, $\left.0^{\mathrm{m}}, 285\right)$. Elle est caractérisée par le fuse-

(18) Cf. A. Grenier, L'argile des amphores, dans Revue des Etudes Anciennes, 1944, p. 336 et Man. Arch. gallo-romaine, II, 2, p. 633, n. 1. 
lage de la panse qui se raccorde au col sans épaulement. Une amphore de ce type incomplète (haut $0^{\mathrm{m}}, 60$; diam. de la panse, $0^{\mathrm{m}}, 29$ ). sans fond ni col, ayant servi de sépulture au III-rI siècle, a été signalée par M. Almagro dans le cimetière à inhumation Bonjoan à Ampurias ${ }^{19}$. Cette forme paraît être le prototype d'amphores analogues plus effilées : amphores de Nyon (forme 48) attribuées par Pélichet ${ }^{20}$ aux dernières années avant l'ère chrétienne, de l'épave de l'île du Levant, découverte par le Dr Piroux (haut. $\left.1^{\mathrm{m}}, 12\right)^{21}$, et amphores, incomplètes du col, de Sanary (diam. $0^{\mathrm{m}}, 21$ ) (Borély 8353).

VI. - Amphore punique (haut. $0^{\mathrm{m}}, 82$; diam. au haut de la panse, $\left.0^{\mathrm{m}}, 15\right)$, à panse cylindrique, col court avec rebord de la bouche en bourrelet, deux petites anses arrondies sur le sommet de la panse (fig. 2, VI). Ln exemplaire entier et une base (L1.2.6.1 et 2 : Borély 8454), trouvés en février 1953 dans le lot des amphores de Sestius.

Ce type d'amphore existe dans le gisement du $\mathrm{Ir}^{\mathrm{e}}-\mathrm{II}^{\mathrm{e}}$ siècle de l'oppidum de la Teste Nègre aux Pennes (Musée Borély)22. Il est abondant sur la còte ibérique du SudFst, à Alicante (Benidorm), Cadix, Port-Mahon, Ibiza, à Melilla ${ }^{23}$, et, à Carthage, caractérise les nécropoles antérieures à la fin des guerres puniques (Bordj-Djedid, Ard-elKheraib) 24. Il doit être rangé, selon la classification de José M. Maña, dans le type G de l'amphore punique, contemporaine des guerres avec Rome et d'origine incertaine. La présence de ce tỵpe dans un navire qui n'a vraisemblablement pas fait escale à Carthage, permet de penser que son origine est italique, ce que confirme la couleur rouge de sa pâte, très cuite, et analogue à celle de la série romaine: on a trouvé des amphores du mème type dans le sud de l'Italie ${ }^{25}$.

\section{Les timbres amphoriques.}

$1^{\circ} \mathrm{La}$ quasi-totalité des amphores romaines (type IV a, fig. 2) porte le nom de Sestius: S E S suivi d'une double devise, l'ancre (fig. 2, IV a et fig. 5) ou le trident (fig. 2 , IV a, et fig. 6), la première plus nombreuse que la seconde, dans un cadre rectangulaire de $0^{\mathrm{m}}, 026 \times 0^{\mathrm{m}}, 015$. La marque à l'ancre a été signalée dans les fouilles terrestres à Besançon et à Lezoux, sans stratigraphie

(19) Las necrópolis de Ampurias, p. 189 et 399, fig. 29 (sépult. 49).

(20) Complément de Dressel dans Revue Suisse d'Art et d'Archéologie, VIII, 1946, p. 189: E. Thevenot, dans Rev. Arch. de l'Est, II, 1952, p. 160.

(21) D. Rebikoff, dans Point de vue - Images du Monde, 5 novembre 1953.

(22) G. Vasseur-Mgr. Challla., $l$. $l$., pl. I, 4 et 5; Déchelette, $o . l$., p. 1002, fig. 420,1 et 2 et p. 1005.

(23) José M. MaNa, Sobre Tipologia de ánforas púnicas, dans Cronica del Vl Congreso arqueologico del Sudeste. Alcoy, 1950 (Cartagena, 1951), p. 204, fig. 1 (type C).

(24) P. Cintas, Céramique punique, tableall III, amphore 313, pl. XXVI, n 313.

(25) G. Vasseur-Mgr. Chaillai, l. l., p. 43. 

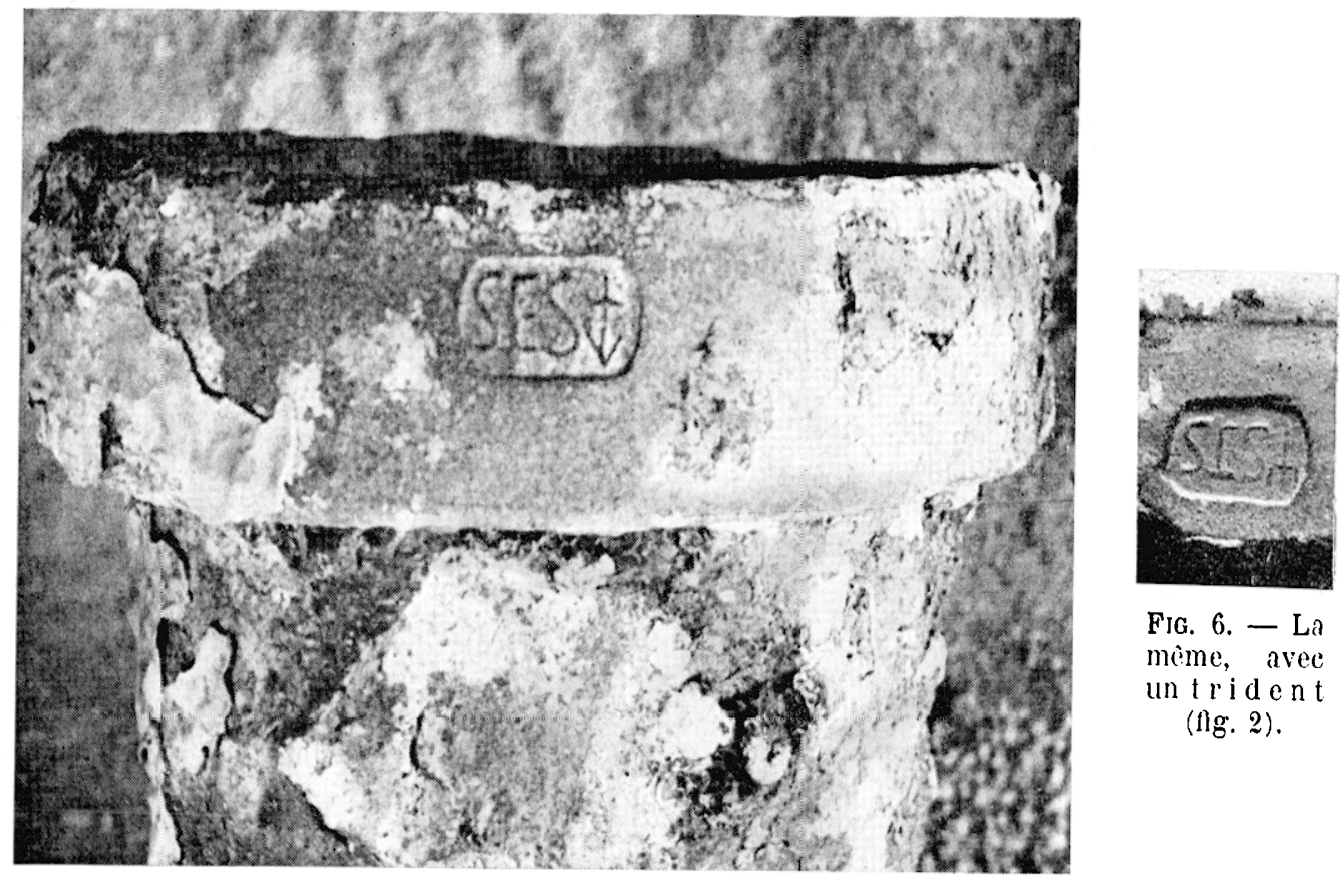

FIg. 6, - La mème, avec un trident (llg. 2).

FIG. 5. - - Marque de SES (avec une ancre) de l'ampnore romiane. type IV a (ilg. 2).

(CIL. XIII, 10002, 470); elle comporte à Besançon, dans l'un des deux exemplaires, une ligature de la dernière lettre avec le T (S E ST), la barre transversale du T coiffant la boucle supérieure de l'S. - Cetle marque doil donc être différenciée d'une autre marque au nom de Sestius. suivie d'une étoile ou d'une palme signalée par Miss Doris Taylor, dans les fouilles de Cosa, en Etrurie : le gisement n'étant pas antérieur à 130 avant J.-C., celle marque est à rapprocher de celle d'Alésia, dans un cartouche de $0^{\mathrm{m}}, 028$ sur col oblique, avec étoile à huit rais; la ligature du T est faite non pas avec l'S, comme à Besançon, mais avec l'E médian, ce qui donne la graphie S ET S, évidemment pour SES Tius ${ }^{26}$. - Lne marque analogue, avec l'ćtoile, trouvée à Bâle, appartiendrait au milieu du $\mathrm{I}^{\mathrm{er}}$ siècle av. J.-C. ${ }^{27}$.

Le synchronisme de ce type d'amphore avec les amphores grecques et la céramique campanienne montre que Sestius à l'ancre el au trident, sans doute armateur

(26) E. Thevexot, Les marques d'amphores d'Alise-Sainte-Reine, dans le XX' Congrès Assoc. bourguignonne des Soc. Sacantes. Semur-en-Auxois, 1949, p. 6; et Importations vinaires en pays bourguignon, dans Rev. Arch. Est, IV, 1953, p. 235. M. Thevenot me signale un second col d'Alísia avec la mème marque.

(27) lbid., p. 235. Il faut egalement signaler une marque SES, sur col d'amphore a argile rouge, sans devise, à Ampurias : M. Almagro, Las Inscripciones ampurilanas griegas, ibéricas $y$
latinas, Barcelone, $1952, \mathrm{p} .208, \cdot \mathrm{n}^{\circ} 205$. 
comme l'indique sa devise maritime, est antérieur à Sestius qui fait suivre son nom d'une itoile ou d'une palme au siècle suivant, _ son fils ou son petit-fils, comme le cas est fréquent dans les familles de négociants romains. Etant donnée la provenance d'une partic de la cargaison, il peut tetre identifié avec quelque vraisemblance avec MAAPKOC CECTIOC de Frégelles, dans le Sud du Latium, qui avait obtenu des citovens de Délos un décret de proxénie dans les premières années du ire siècle avant J. - C. 28.

$2^{\circ}$ La seconde série d'amphores romaines (type IVb, fig. 2) porte la marque estampée sur l'épaule, dans un cartouche rectangulaire de $0^{\mathrm{m}}, 049 \times 0^{\mathrm{m}}, 013$, DAY.ATEC, avec ligature des deux dernières lettres du premier groupe et des trois premières du second, sans doute deux noms accolés D.AV.ATEG (fig. 2, IVb et fig. 7).

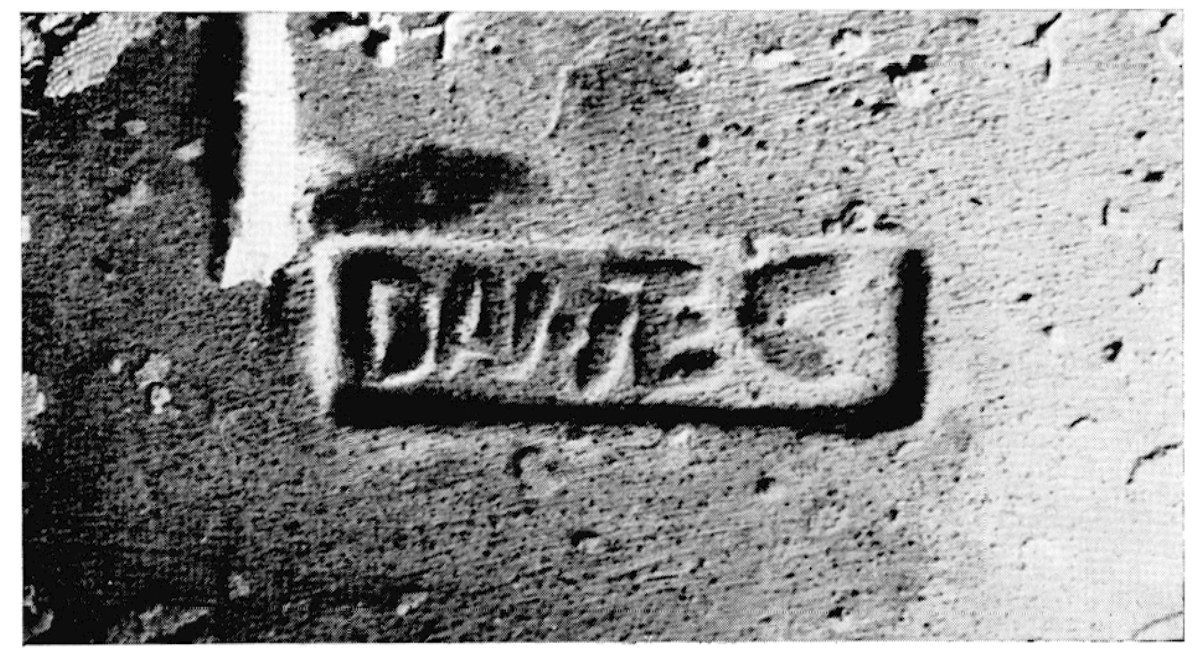

Fic. 7. - Marque de l'amphore romaine, type IV b (fig. 2).

$3^{\circ}$ Une amphore sans timbre porte sur le rebord du col à lèvre oblique, une marque de trois lettres gravées au stylet avant cuisson : R N T.

$4^{\circ}$ Les graffites, peu apparents par suite de l'érosion, paraissent être très rares; une amphore, sans col, porte un E sur la panse (LI.2.325); une autre sur l'épaule.

\section{Fermeture des amphores et marques de négociant.}

S'il n'a pas encore été possible de recueillir de bouchons d'amphore grecque ou gréco-italique, la conservation d'opercules de fermeture des amphores

(28) Je remercie M. J. Coupry de la précision de datation qu'il a bien voulu me donner au sujet de cette inscription (P. Roussel, Ins. gr., XI, IV (Délos), 1914, 757). 
de Sestius montre que le bouchage était identique à celui qui a déjà été signalé, au $\mathrm{I}^{\text {er }}$ siècle av. J.-C., à Anthéor et alx Saintes-Marie-de-la-Mer ${ }^{29}$.

L'obturation était obtenue par un bouchon de liège peu épais $\left(0^{\mathrm{m}} 005\right.$ a $\left.0^{\mathrm{m}}, 015\right)$, parfois doublé, insćrć dans le col à environ $0^{\mathrm{m}}, 15$ de l'embouchure et retenu par l'une des cannelures horizontales formant étranglement d'arrêt. Des fragments de rondelles de liège ont été recueillis dans les opérations de dévasage des amphores "gréco-italiques ", dont la fermeture devail être identique à celles de Sestius. Au-dessus de cette rondelle, en contact avec le vin, l'opercule, formant " cachet ", était constitué par un mélange de chaux et de pouzzolane sur lequel était imprimé, deıx fois répété, le nom du négociant à l'aide d'un cachet de bronze semi-lunaire, laissant apparaître au centre un tenon.

Parmi de nombreux exemplaires corrodés, d'épaisseur variable $\left(0^{\mathrm{m}}, 02\right.$ à $\left.0^{\mathrm{m}}, 05\right)$, un bouchon porte le nom complet de L.TITI.C.F. (L.Titius Caii filius), confirmé par plusieurs exemplaires en partie effacés (fig. 8).

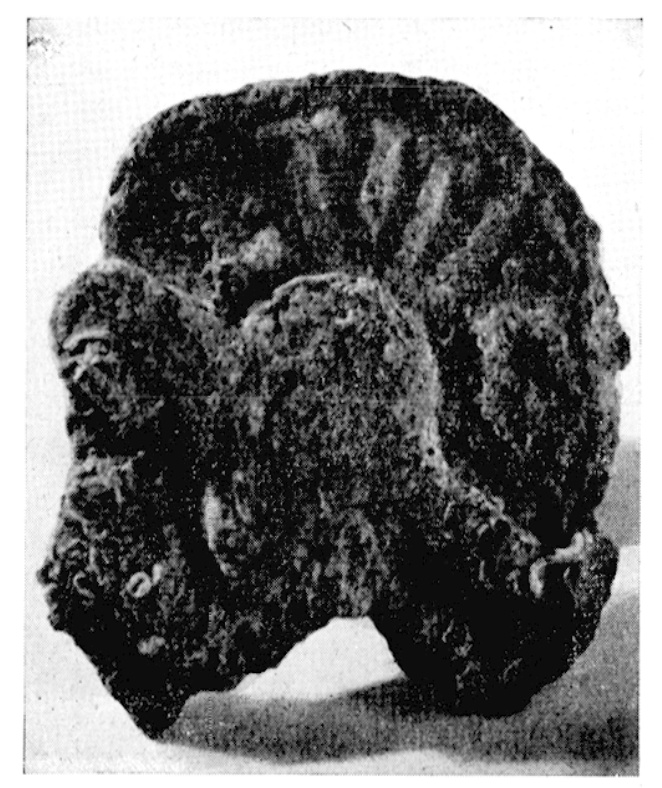

Fig. 8. - Bouchon de mortier de chaux portant la marque de L. Titius, fils de Caius, provenant d'une amphore italique de Sestius.

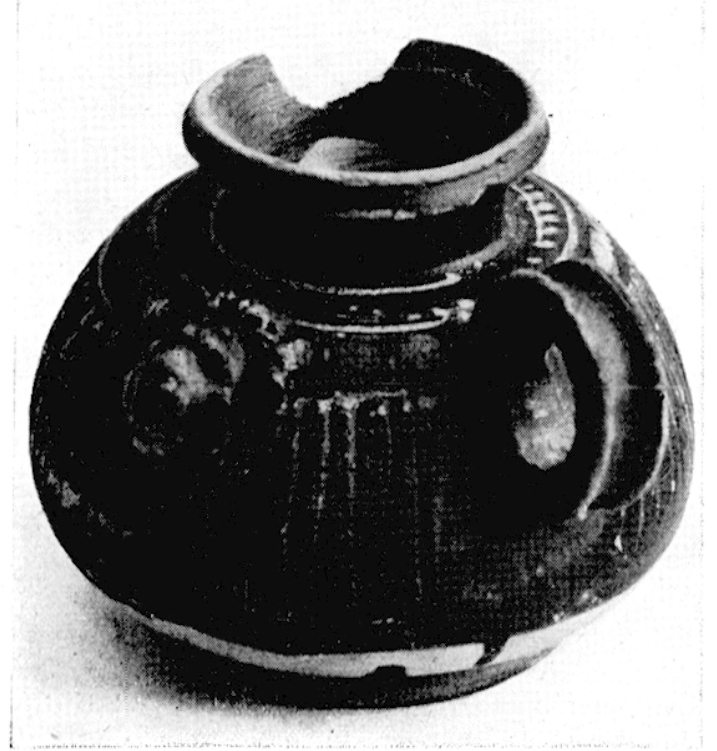

FIG. 8 bis, - Guttus à muffle de lion (voir les dessins de ce vase fig. 12, à droite, p. 51).

(29) Gallia, VI, 1948, 1, p. 213, et VIII, 1950, p. 129. Voyez également les marques publiées par M. AlmaGro, Las Inscripciones ampuritanas, p. 227, n ${ }^{\text {os }} 252$ à 255. 


\section{Enduit intérieur.}

Les différentes séries d'amphores présentent toutes les traces d'un enduit de coulour noire de bilume, uniformément réparti sur toute la surface intérieure et débordant parfois sur le rebord du col. L'aspect est identique dans les amphores italiques et dans les amphores rhodiennes. L'analyse faite pour les premières montre que la couleur noire vient de la pyrogénation de la résine " mastic ", qui, à la suite d'une fusion prolongée, au dessus de 90 degrés, donne un vernis qui s'itale sur toute la surface de la terre cuite. la rendant imperméable. La recette de cette résine nous est donnée par Pline: il vante les sucs produits en Orient, parmi lesquels il place en premier lieu, comme étant le plus fin, celui du térébinthe, puis celui du lentisque, dénommé " mastic " (produit en particulier à Chio) et ensuite celui du cyprès, dont la saveur est àpre ${ }^{30}$. Mais nous savons qu'en Italie. on utilisait aussi pour enduire les grandes jarres, la poix bruttienne, produit de distillation du faux sapin ou epicea ${ }^{31}$.

Il sera donc intéressant de faire analyser les différents enduits trouvés en Gaule romaine, où le goùt du " vin résiné " était apprécié, ainsi que l'atteste l'enduit interne d'un gobelet à trois anses provenant de l'épave du port d'Antibes, du III $^{\mathrm{e}}$ siècle de notre ìre ${ }^{32}$.

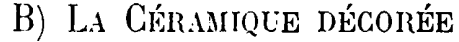

Elle appartient également à des provenances différentes, de Grèce et du Sud de l'Italie, et peut se classer en deux séries:

I. - Bol à relief' hellénistique, dit de Délos ou de Mégare, à vernis mat et rebord rentrant vers l'intérieur, orné d'un calice de feuillage et d'une bande étroite d'entrelacs et de rosettes. La pâte jaune clair, peu cuite, micacée, est différente des bols de ce type à vernis rouge corallin et à pâte bien cuite, qui sont peut-être de fabrication ilalique.

Les lieux de fabrication de cette vaisselle ne sont pas déterminés. Un tesson avec

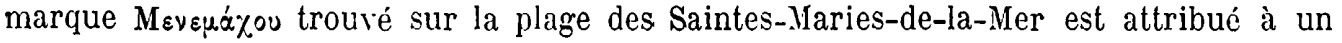
atelier de Délos 33. - La typologie de ces bols les a fait classer par F. Courby dans la seconde moitié du irie siècle av. J.-C. 34. La classification des vases mégariens de

(30) R. Marcille, La résine et la poix de Pline, dans Revue Tunisienne, 1941, p. 220.

(31) N. II., XIV, 25; XVI, 21.

(32) F. Benoît, L'archeologie sous-marine en Provence, Rev. ét. lig., 1952, p. 256, flg. 21, 6.

(33) F. Courby, Les vases grecs a reliefs, 1922, p. 393. Cf. FOR, V, 398; et F. BExoî, L'archéologie sous-marine en Provence, $l$. l., p. 251 et 286, n. 3.

(34) 0. l., p. 279, fig. 47,2 et p. 373 , etc., et fig. 76,3 et 9 . 
Mayence par Th. Kraus les rapproche de bols allant du milieu du III $^{\circ}$ à la première moitié du $\mathrm{Il}^{\circ}$ siècle ${ }^{35}$. I.e synchronisme du matériel du bateau permet d'assigner à ce type le début du II ${ }^{e}$ siècle.

II. - La vaisselle campanienne, dont plus d'un millier de pièces ou de tessons corrodés avait été remonté des couches superficielles en 1952, est actuellement représentée par plus de 5.000 pirces. Elle se classe en 22 séries de types différents, chaque série comprenant un échantillonnage de grandeur allant parfois jusqu'à sept variélés. La quasi-tolalité est en argile rose (type A de la classification de Lamboglia $\left.{ }^{36}\right)$; cependant il faut signaler quelques échantillons de coupelles et de pyxides en argile gris-noisette (type B rose cendré) et la grande patère à rebord droit, à vernis mat et pâte grise (type C).

La présence de certaines formes qui appartiennent encore au III $^{\mathrm{e}}$ siècle et disparaissent au II ${ }^{\mathrm{e}}$, le kylix ou coupe à pied élevé et double cordelière nouée sur le sommet, le plat à poisson, le balsamaire à panse bombée à la partie
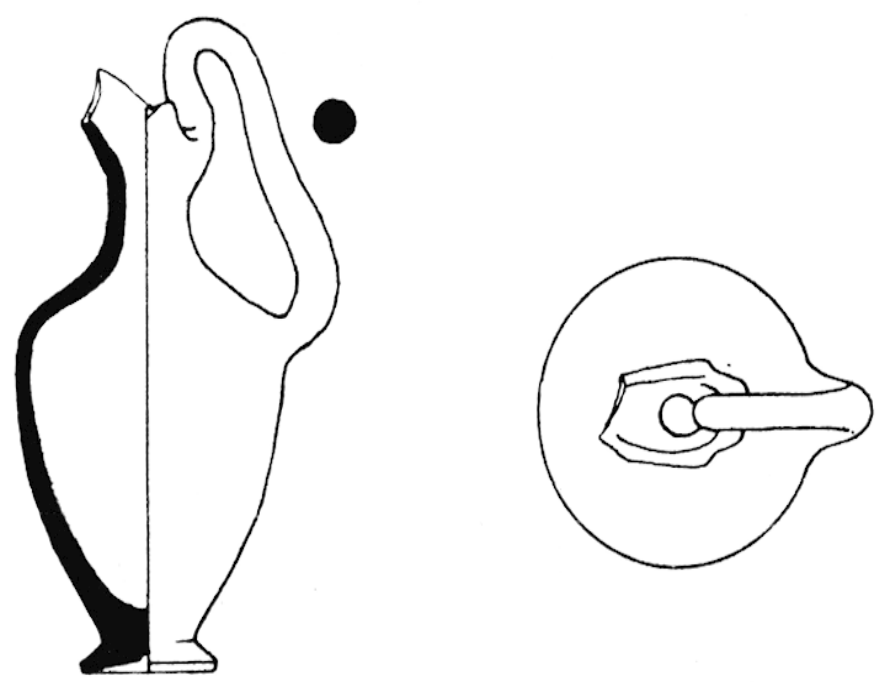

FIcr. 9. - Petite oenochoé campanienne trouvée en 1954, profll et plan, haut. : $0 \mathrm{~m}, 12(1 / 2$ grandeur.)

supérieure, le bol, l'œnochoé 'fig. 9), le guttus caréné, à tête de lion, parfois cannelé, et la lampe campanienne, confirment la datation générale de la céramique plus courante, coupes et coupelle's, qui se perpétuera jusqu'au i ${ }^{\text {er }}$ siècle.

Il est encore a.ıficile de localiser les centres de production de cette céra-

(35) Megarische Becher im Römisch-germanischen Zentralmuseum zu .Jainz, Mainz, 1951, pl. 2, fig. 2 à 4.

(36) Per una classificazione preliminare della reramica campana, dans Atti del $1^{\circ}$ Congresso internaż. di Studi liguri, 1950, p. 139 à 206. 
mique dont la renommíe était mondiale, au dire de Pline ${ }^{37}$ et dont la diffusion est surtout importante dans le sillon du Rhône et de la Saône, jusqu'à Château-Salins dans le Jura. Le bol est fréquent à Pompéi et à Minturnes ${ }^{38}$. La similitude de pâte, de forme et de décoration du kylix avec ceux qui ont été trouvés à Ischia, confirme l'origine napolitaine du fret italique : les fouilles de Büchner (au museo dell'Isola) ${ }^{39}$ permettent une comparaison intéressante de la décoration interne du kylix, faite de bandes blanches avec rinceau de lierre incisé et petites feuilles cordiformes à rehaut blanc.

La décoration générale est constituée de palmettes et de rosettes estampées, réservées à l'ornementation des coupes et coupelles : palmetles appartenant à 10 modèles différents et rosette de 6 à 8 feuilles séparées ou non par des points (5 modèles différents).

Deux pièces, la lampe et le guttus, peuvent être datées par comparaison avec le matériel funéraire; leur forme est caractéristique du III $^{\mathrm{e}}-\mathrm{II}^{\mathrm{e}}$ siècle :

a) deux lampes, présentant de légères variantes, appartiennent au type campanien, à réservoir circulaire haut et caréné, muni d'une corne latérale, sans anse; le

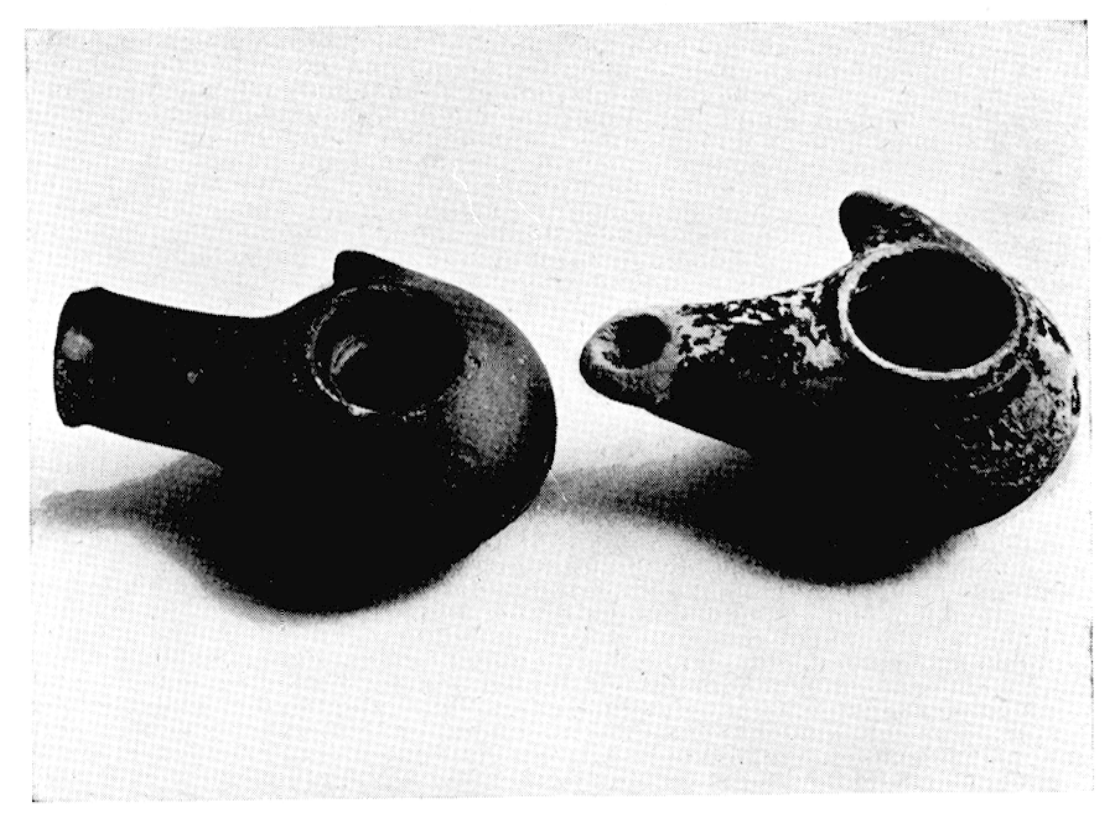

Fig. 10. - Lampes campaniennes à corne latérale. A gauche : flg. 11, à gauche; à droite : flg. 11, à drolte.

(37) $N$. H., XXXV, 160-161.

(38) Voy. les bols des fouilles de Kirsopp à Minturnes et d'Ampurias : N. Lavboglia, $l$. $l$, p. 180 , forme 31 et p. 181 , forme 32 .

(39) G. BüchNer, A. RitTirann, Origine e passato dell' Isola d'Ischia, Naples, 1948, p. 57. 
bec détaché de la cuvette est proéminent (fig. 10 et 11 ) ${ }^{40}$. L'une d'elles (long.: $0^{\mathrm{m}}, 096$; haut. du réservoir : $\left.0^{\mathrm{m}}, 031\right)$, à couverte rougeâtre tirant au noir, a un bec élargi par un double saillant et terminé par une ligne légèrement convexe; la cuvette circulaire et profonde mesure $0^{\mathrm{m}}, 015$ (fig. 10 , à gauche et fig. 11, à gauche). L'autre (long. : $0 \mathrm{~m}, 10$; haut. du réservoir : $\left.0^{\mathrm{m}}, 037\right)$, à vernis noir, avec corne plus saillante qui fait prévoir la lampe delphinoïde; son bec à angle obtus constitue le prototype du "bec d'enclume" de la lampe du $\mathrm{i}^{\text {er }}$ siècle. Le fond de la cuvette d'alimentation a disparu, l'orifice supérieur ayant le même diamètre que dans le modèle précédent. A la partie postérieure
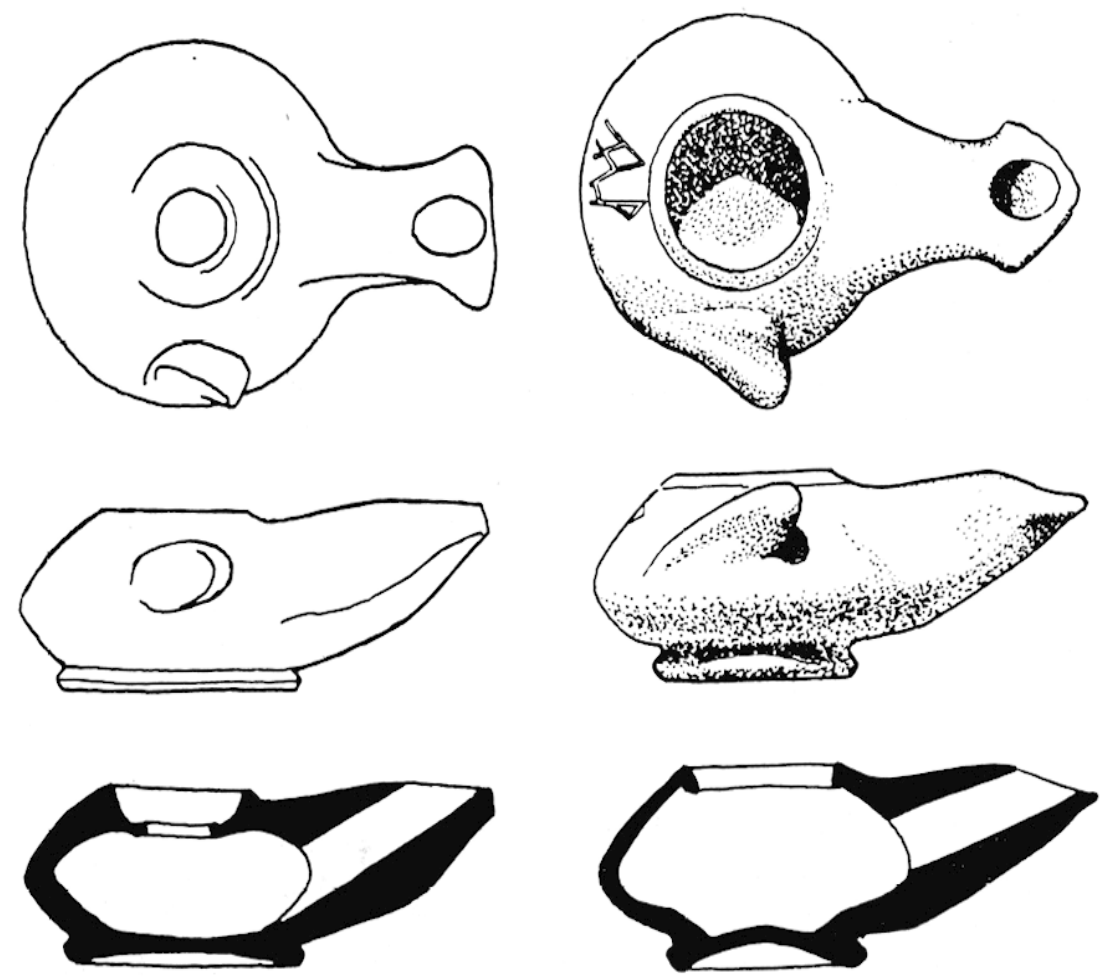

Fig. 11. - Lampes campaniennes $: 1 / 2$ grandeur) A gauche : fig. 10, à gauche: ì droite : fig. 10 , à droite.

du réservoir est un graffite profondément gravé de deux lettres de $0^{\mathrm{m}}, 015$ de hauteur (A P, alpha à barre transversale brisée, et ro caractérisé par la petitesse de sa boucle; (fig. 10, à droite et fig. 11, à droite).

b) douze guttus à mufle de lion, à panse carénée et anse verticale (fig. 12, à gauche), à pâte rouge brique et vernis noir métallique (diam. : $0^{\mathrm{m}}, 11$; haut.: ()$\left.^{\mathrm{m}}, 06\right)$ et un guttus de forme plus élégante, à panse cannelée, bọdé d'un épaulement horizontal d'où

(40) J. Toutain, s. v. Lucerna, Dict. Antiq., III, p. 1322 (II s.). On en rapprochera les lampes grecques du Musée Borély (P. Jacobsthal et E. Neufrer, Gallia Graeca, dans Préhistoire, II, 1933, fig. 32, $c$; celles du Musée de Girone (P. de Palol, Memorias de los Museos arqueol. provinciales, 1948-49, Madrid, 1950, fig. 101,1); et celles des tombes puniques de Carthage (P. CINTAS, Céramique punique, p. 177 et pl. XLII, 23 à 27; XLIII, 28 et 29; et tableau III, lignes 8-13). 


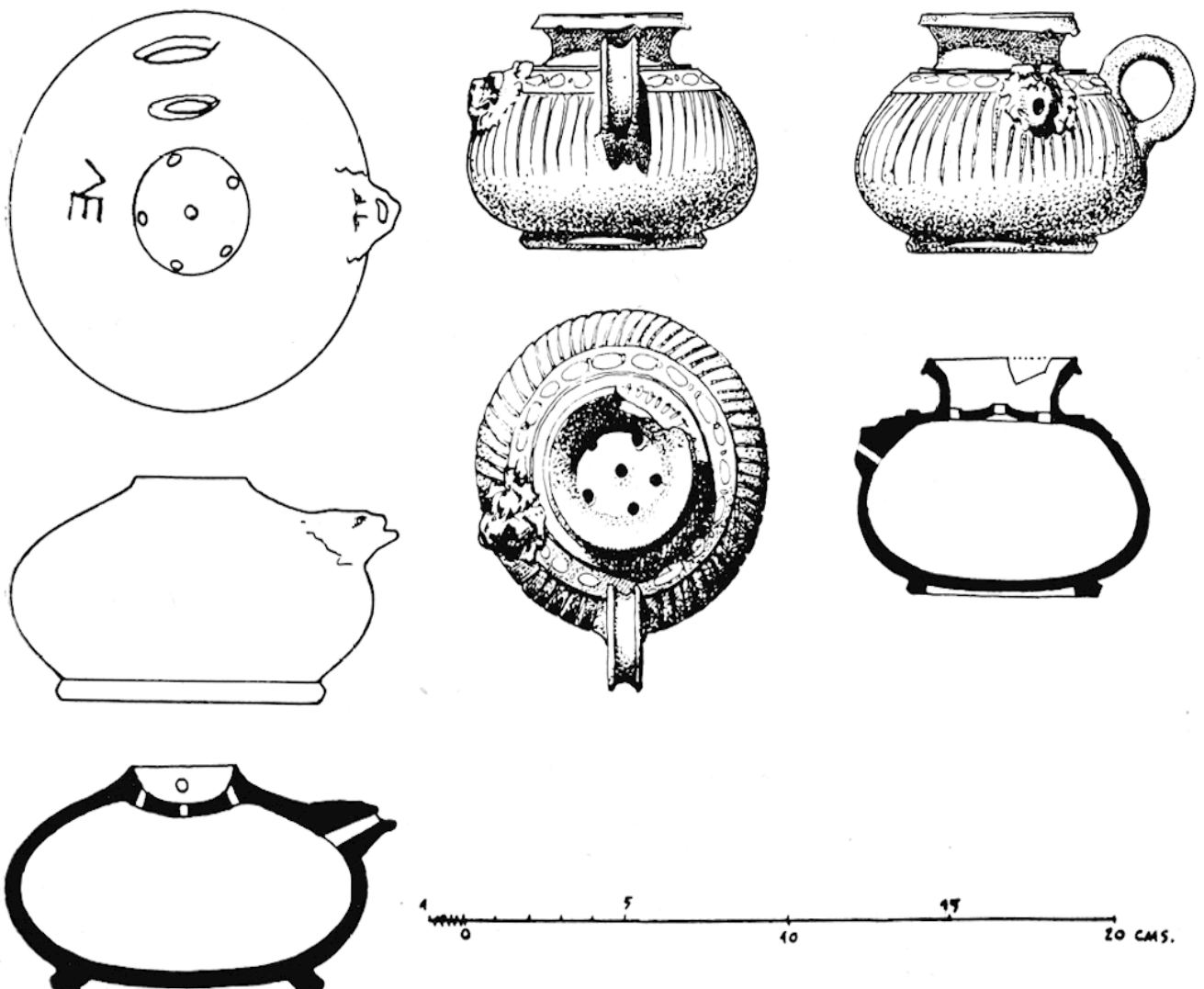

FIG. 12. - Guttus à muffle de lion : à gauche, avec graffite; à droite, = fig. 8 bis (p. 46).

se détache la curette de l'entonnoir à bord relevé et évasé (diam.: $0^{\mathrm{m}}, 085$; haut.: $0^{\mathrm{m}}, 065$ ); la pâte de ce dernier à argile rose est couverte d'un vernis mat et ornée d'une décoration peinte à rehaut blanc, rangée de perlettes et de piécettes en haut de la panse et denticules sur l'épaule (fig. $8^{\text {bis }}$ et fig. 12, à droite). Ce dernier modèle se rapproche des guttus trouvés dans les tombes puniques du Cap Bon, datés des III"-II" siècles ${ }^{41}$.

\section{Graffites.}

Quelques-uns de ces vases portent des graffites faits après cuisson, à l'extérieur (bols, coupes et coupelles): deux lettres ligaturées, un signe cursif à trois et une fois quatre jambages, en forme de $\mathrm{N}$, toujours ouvert, suivi d'un $\mathrm{E}$ en capitale, lié au dernier jambage de la lettre précédente (fig. 13).

Le même groupe se relrouve, en capitales, sur le col d'un petit vase à anse, en terre grise, $\mathrm{ME}$; la régularité de son tracé permet de penser que les signes précédents ont une valeur analogue. Un signe semblable à trois jambages JM,

(41) P. Cintas, o. l., p. 169 et pl. XXXVII, 399-400, et tableau III, 12. 

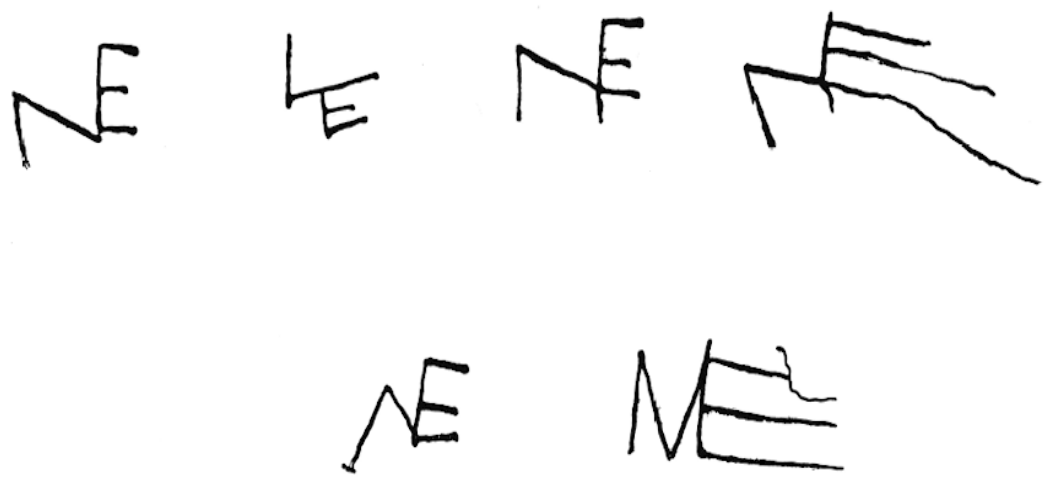

FIG. 13. - Graffites sur céramique (gr. nal.). Les six premiers sur guttus, coupes, coupelles et bols; le dernier sur vase en terre grise. Pour le 1er signe, cf. fig. 12, à gauche.

fait avant cuisson, a été signalé sous l'atlache de l'anse d'une amphore de l'épave A d'Anthéor ${ }^{42}$. Cette marque est peul-être' en écriture rétrograde, les amphores provenant de Pouzzoles étant caraclérisćes par la graphie osque du timbre du négociant, imprimé sur les bouchons de pouzzolane au nom de M.C.Las(sius), de la première moitié du $\mathrm{I}^{\mathrm{er}}$ siecle av. J.-C.

S'il est difficile de voir dans le graffite A P de la lampe campanienne (fig. 11, à droite) une marque de l'usager', a cause de l'état de netleté du bec qui ne porte pas trace de brûlure, cette explication est encore moins vraisemblable ici, en raison de l'uniformité du signe. La marque NE, répétée deux fois sur un guttus, sur la panse (fig. 12, a gauche; fig. 13, $1^{\text {er }}$ signe) et sous le pied, est peut-être une inadvertance du graveur. Marque de fabrique ou d'échantillonnage (e[xemplum]) ? Marque du négociant faite dans l'entrepòt où il a fait son achat (n[umerus $\rceil e\lceil x a c t u s])$ ? Ou marque de contrôle pour l'exportation, certifiant la perception du portorium (visa de l'exactor) ${ }^{43}$ ? L'apposition de la marque paraît antérieure à l'emballage de la vaisselle, puisqu'elle est sur le flanc extérieur des bols et des coupes, qui étaient empilés, ainsi que le montrent plusieurs groupes de bols et de coupes agglomérés.

C'est un graffite d'un tout autre genre, également tracé après cuisson, qui se lit sur une dizaine d'exemplaires du gobelet à embouchure étroite (fig. 14 et 15), dans un encadrement figurant une tige spiralée de lierre avec rehauts

(42) D'après M. Philippe Diolé, F. Benoit, L'archéologie sous-marine, l. l., p. 264. On rapprochera de ce signe un graffite comportant également un $E$ lić à une lettre à deux jambages, sur un kylix du ve siècle découvert à Athènes (initiales du proprictaire ?) : C. Rosbuck, Pottery from the North slope of the Acropolis, dans Ilesperia, IX, 1940, no 307, fig. 51; cf. L. TALCoTt, ibid., V, 1935, p. 353.

(43) Cf. S. J. de LaET, Portorium, Bruges, 1949, p. 374, n. 3. 


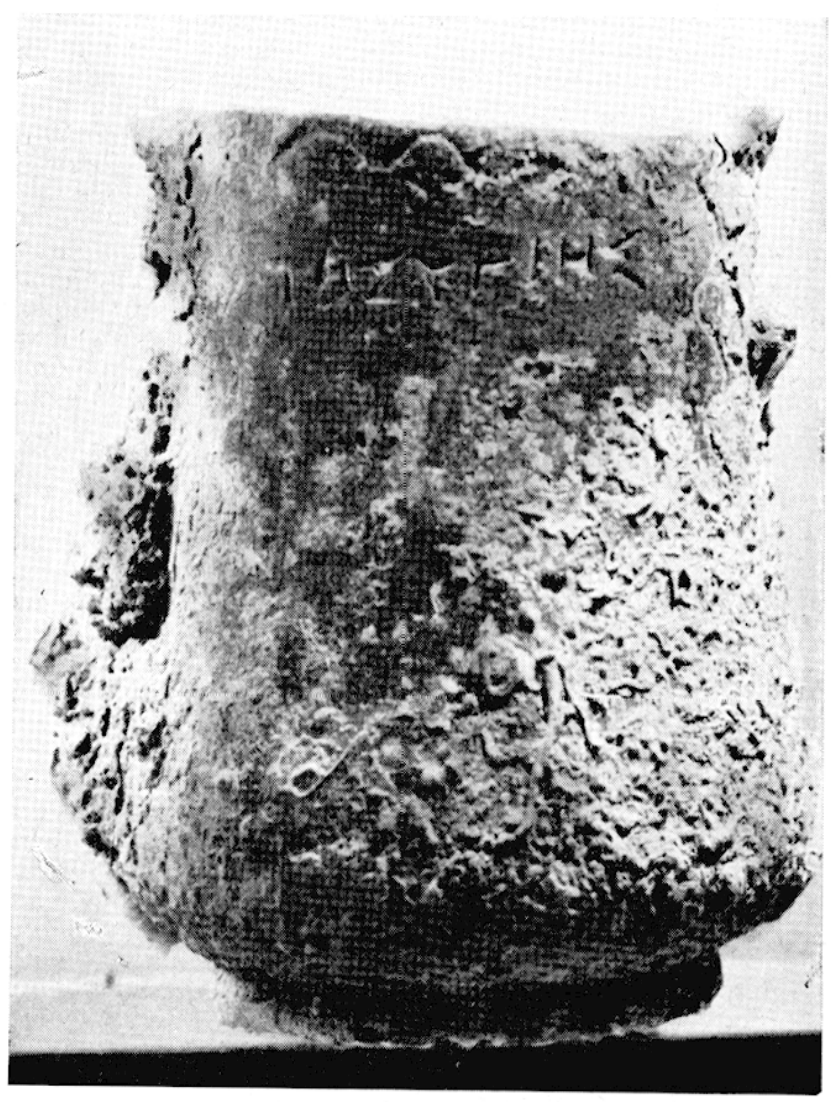

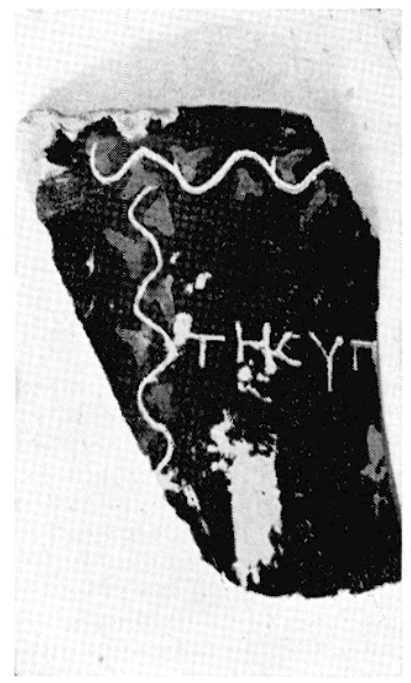

FIG. 15. - Graffite d'Hygie sur tesson de gobelet.

FIG. 14. - Graffite d'Hygie sur gobelet (à gauche).

blancs de feuilles cordiformes, sur le type décoratif dćjà rencontré à l'intérieur des bols :

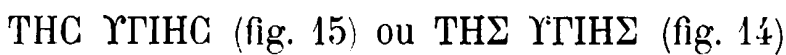

la première graphie plus fréquente que la seconde (8 exemplaires contre 2).

Graffite sur gobelets destinés à la vente, plutôt que sur la vaisselle de l'équipage. L'invocation à la déesse de la Santé, Hygie, au génitif, devait être populaire en Grande Grèce comme elle l'était en Grèce, à l'époque classique, chez les buveurs qui vidaient à la fin du repas, après s'être lavé les mains, la

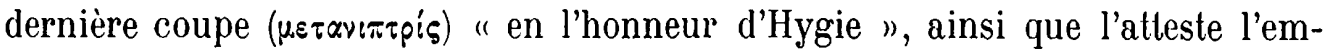
ploi de cette locution au génitif, empruntée à la langue parlée, chez les auteurs comiques des $\mathrm{V}^{\mathrm{e}}$ et $\mathrm{IV}^{\mathrm{e}}$ siècles ${ }^{44}$.

(44) Voy. les exemples donnés par H. G. Liddell-R. ScotT, A Greek-English Lexicon, Oxford,

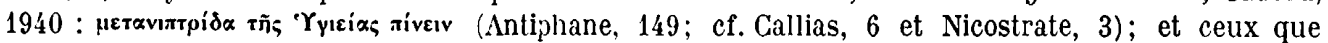

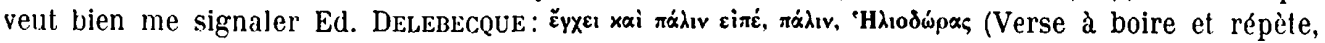

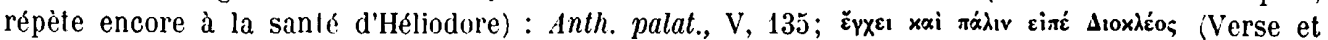
répète à la santé de Dioclès): Callicaque, Epigram., 29. 
La forme contractée, conforme à la langue grecque d'ćpoque romaine en Grande Grèce, mais en dialecte ionien (' $\Upsilon$ Y'in), appartient donc à un langage populaire, de tradition ionienne, parlé en Campanie à la fin de la République. Celte invocation à la Santé, qui patronne le vin de Campanie, religieuse dans sa forme qui n'a pas encore adopté le style direct de l'apostrophe " à votre santé ", montre la relation étroite entre le marchand de vin ou l'exportateur et le fabricant de gobelets, qui est peut-être le même négociant ${ }^{4 \bar{s}}$.

Fernand Bevolt.

(45) Cf. en Gaule au Ier siècle le Trévire marchand de vin et de céramique (ars cretaria) : $C I L$, XIII, 2033. On a remarqué que les marques d'amphores portaient parfois à Délos le nom de négociants connus par les textes épigraphiques: J. HATZFeld, Les trafiquants italiens dans l'Orient hellénique, Paris, 1919, p. 145. 